\title{
USE OF FEM NUMERICAL SIMULATION APPROACH FOR SURFACE ROLLING PROCESS CONTROL
}

\author{
Vitalijs Zaharevskis, Aleksei Kurushin, Olegs Kovzels
}

SIA “Centre Composite", Latvia

vitalijs.zaharevskis@composite.lv, aleksej.kurushin@composite.lv, olegs.kovzels@composite.lv

\begin{abstract}
Surface rolling is an effective method to improve the detail fatigue and damage tolerance characteristics especially in stress concentration zones for metal parts made from high strength steels. The main focus of this study is on applying a virtual simulation to control the surface hardening after the rolling process. Effective control of hardening quality is still an issue in modern engineering. Due to large variety of stress concentrators in details (smooth shafts, fillets, mating) that require hardening it is a problem to create a universal method for controlling the quality of the hardening process. Each individual case requires series of expensive tests and researches. This article discusses the use of the finite element modelling (FEM) for the rolling process quality control after hardening. The use of the FE method accompanied with the ring-cut experimental method allows minimizing financial and time costs of hardening quality control. The FE sample is cut into rings and then transversely dissected. The ring diameter is reduced due to residual compressive stresses inside the ring. The indicator of qualitative hardening in the FE model is the distribution of residual compressive stresses throughout the hardened area. The obtained results (decreased diameter) are verified by experiments using the ring-cut method. Shaft surface rolling is modeled by MSC Marc/Mentat 2016 software and the ring-cut method to be described as an experimental arbitrary method for the hardening quality control. The methodology described in this article can be effectively applied to the control of hardening quality after surface rolling and its implementation in manufacture can significantly reduce the financial and time costs.
\end{abstract}

Keywords: rolling, material hardening, fatigue life.

\section{Introduction}

Surface rolling is an effective method to improve the detail fatigue and damage tolerance characteristics especially in stress concentration zones for metal parts made from high strength steels $[1 ; 2]$. For hardening quality control on manufactory the following methods are used: surface roughness control after hardening, hardening technology control, control ring specimen's deformation [3], slitting method [4]. Surface roughness control is performed by a special tool or standardized sample. Surface roughness is inspected on the first and last parts from the production series. Hardening technology control consists of periodical inspection of hardening equipment and staff personnel competence. The ring-cut method, described in "Materials and methods" chapter of this article is used as well. In laboratory hardening quality could be controlled by analyzing the material structure in the plastically deformed layer in an electronic microscope, which allows seeing the hardened area in high resolution.

In this article was researched in the ring-cut method. Material surface hardening quality is an important characteristic, and has a crucial effect on the detail's service properties, wherein hardening quality management is a complicated task. To solve this problem, series of expensive experiments and special equipment are needed. Thus, the express method is needed for hardening quality management during the manufacturing process.

High quality surface hardening increases the part's service life several times. Hardening quality is defined by the following parameters:

1. uniformity of the hardened layer;

2. thickness of the plastically deformed layer;

3. residual stress rate.

In Fig. 1 one can see an example of non-uniform hardening, which appeared because of initial gap between the roller and the shaft and wrong rolling parameters. Residual plastic strain distribution was calculated using the FE method and is shown on the right. The center and sides of the groove stayed unhardened. That kind of hardening will not have a significant effect on the part's fatigue strength.

Hardening quality depends on a few factors [5-7]. The first factor relates to selection of the rolling parameters, the second is the manufacturing factor. 


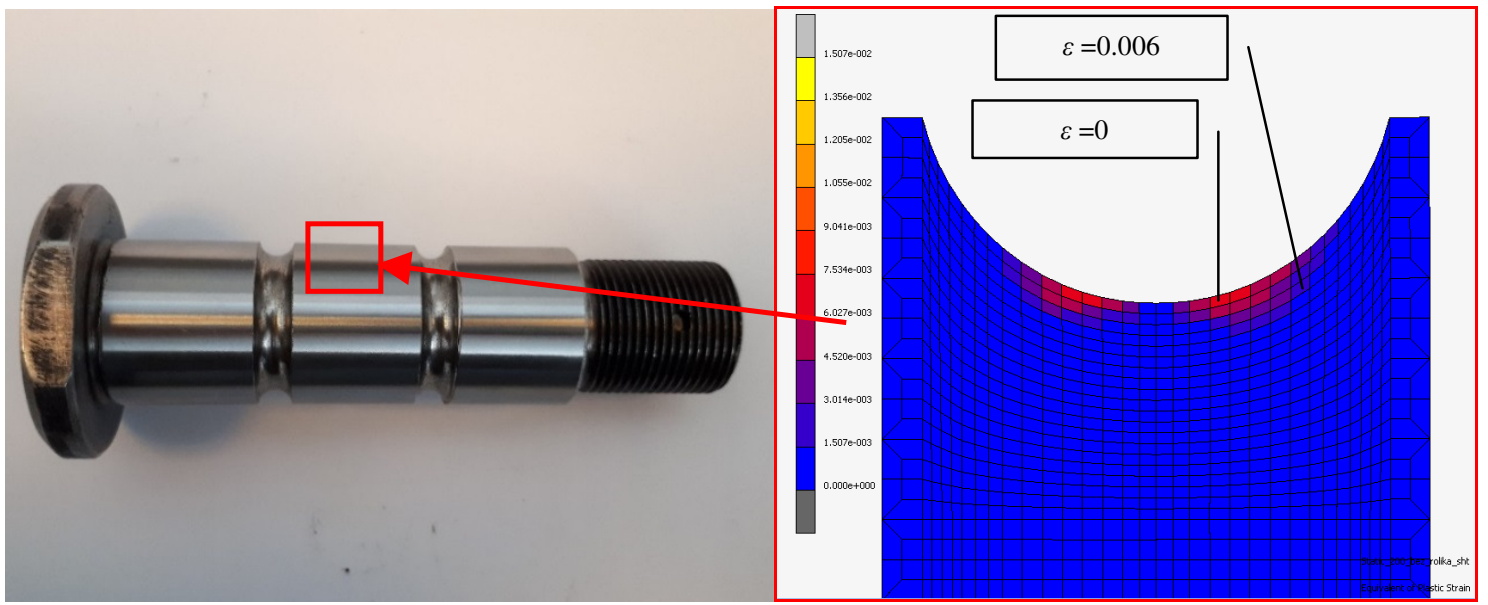

Fig. 1. Non-uniform hardening

The rolling parameter factor consists of the following characteristics:

1. roller radius;

2. roller section radius;

3. rolling load;

4. number of rolling iterations;

5. horizontal speed (if necessary).

In the first iteration, the rolling parameters are selected in accordance to $[8,9]$. After the FE analysis the rolling parameters could be redefined.

The manufacturing factor is related to the roller and shaft geometry and manufacturing quality. An example of wrong roller fitting with the initial gap between the roller and the shaft is shown in Fig. 2 (left). In Fig. 2 (right) the horizontal surface on the roller section is shown, this surface appears due to wear of the roller. These defects have a negative effect on the hardening quality.
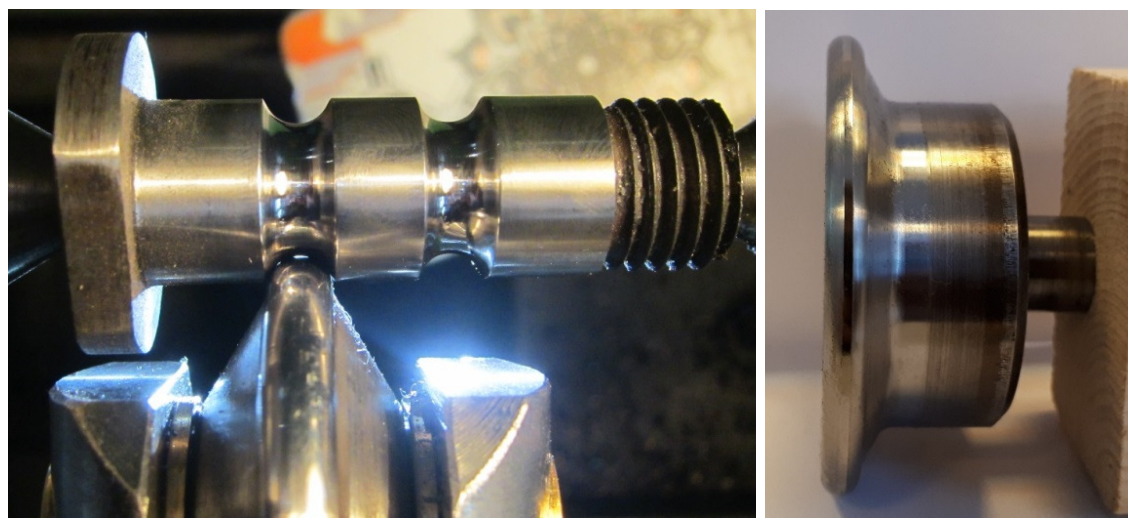

Fig. 2. Defects

The main case of this study is development of the criterion, which will allow to control hardening quality and will help select optimal rolling parameters by using the finite element (FE) method.

\section{Materials and methods}

For hardening quality management and FE analysis verification the ring-cut method can be used. This method allows to make an arbitrary analysis of residual stress in the material. The main benefit of the ring-cut method is its availability, it can be easily applied to the manufacturing process.

The main idea of the ring-cut method is that residual compressive stress appears in the material after hardening. If you cut the shaft into rings and then transversely dissect them, the ring diameter will reduce due to compressive stresses inside the ring. An example of rings after cutting dissection is shown in Fig. 3. The detailed description of this method can be found in [10]. 


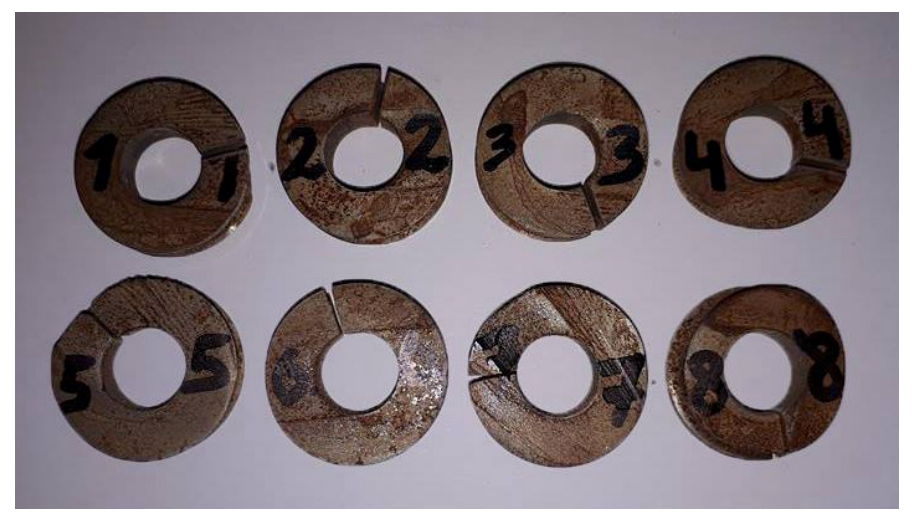

Fig. 3. Rings after cutting

Quality management procedure is described below.

1. Control sample (shaft) is hardened by approved technology.

2. Hardened sample is cut into rings.

3. Ring's diameters are measured.

4. Rings are dissected.

5. Ring's diameters are measured.

6. Decrease of ring's diameters after dissection is calculated.

7. Collected data are statistically analyzed.

Complete FE simulation was performed using MSC Marc and Mentat software. The calculation scheme is shown in Fig. 4. Only a local part with the groove was modelled, because surface hardening of the groove does not affect displacements, stresses and strains of local zones. The model contains two bodies: a roller (modelled as a rigid surface, loaded by rolling force) and a shaft (deformable body with stress - strain material curve, shown in Fig. 5). The shaft was modelled with HEX8 elements. To ensure uniform hardening of the groove, groove hardening was carried out in 5 positions with different rolling angles (Fig. 6). At each angle the shaft completed 3 full turns. This overlapping is needed in order to reach the best parameters of the plastically deformed layer and surface roughness on the actual specimen [9], the same hardening regime was simulated using the FE method. Rolling force of $4000 \mathrm{~N}$ was selected according to the recommendations from [8] as optimal force for our specimen.

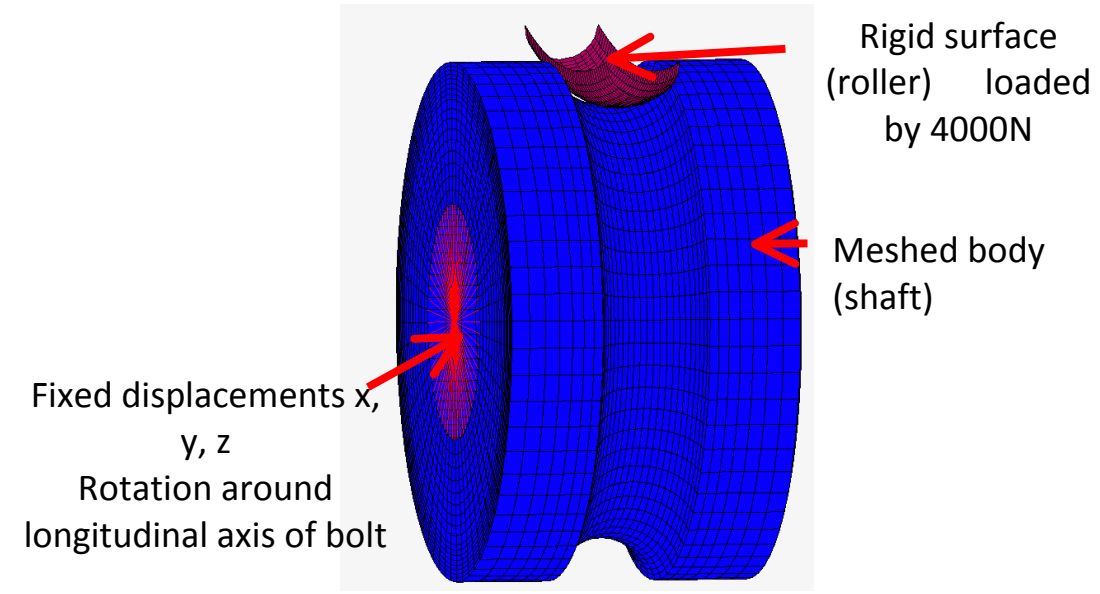

Fig. 4. Calculation scheme

The diameter of the shaft in the groove was measured after hardening, after that, the FE sample was cut into rings and then transversely dissected (Fig. 7). The ring diameter was re-measured after it reduced due to compressive stresses inside the ring. As a result, the calculated diameter reduced by $0.038 \mathrm{~mm}$ after rolling.

To validate the FE analysis an experiment was performed. Hollow shafts with four grooves were ordered at the metalworking manufactory (Fig. 8). 


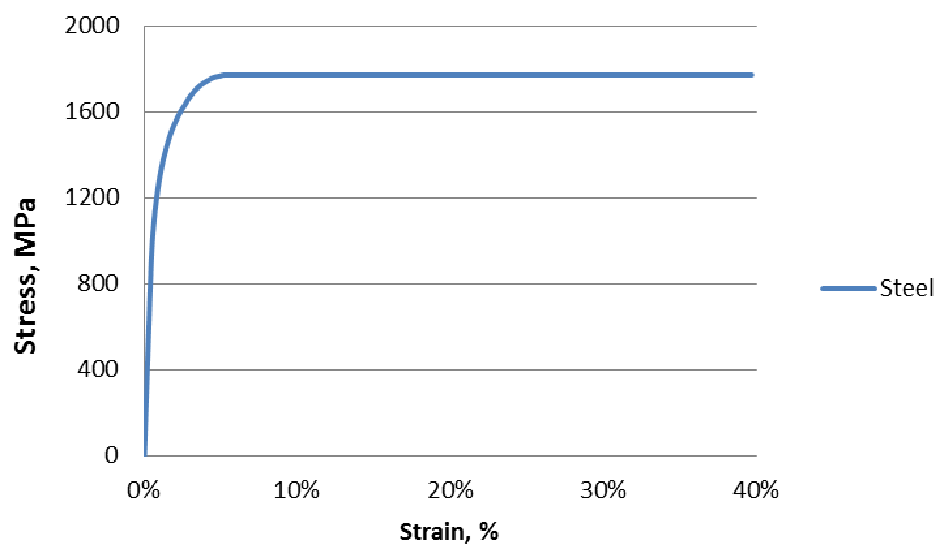

Fig. 5. Stress - strain curve
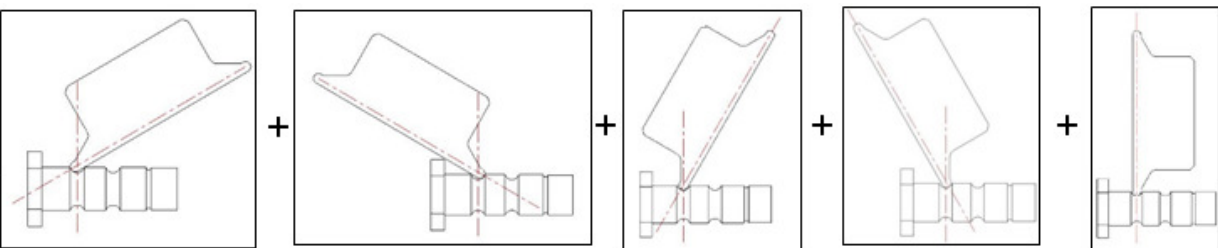

Fig. 6. Roller position under different angles

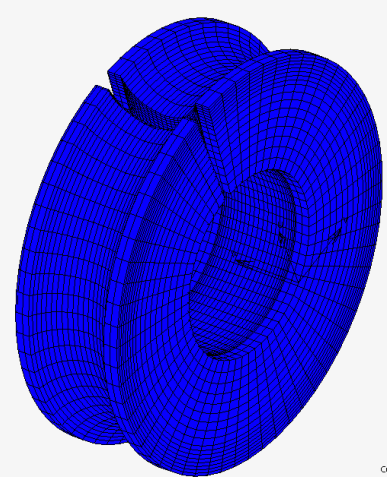

Fig. 7. Transversely dissected ring

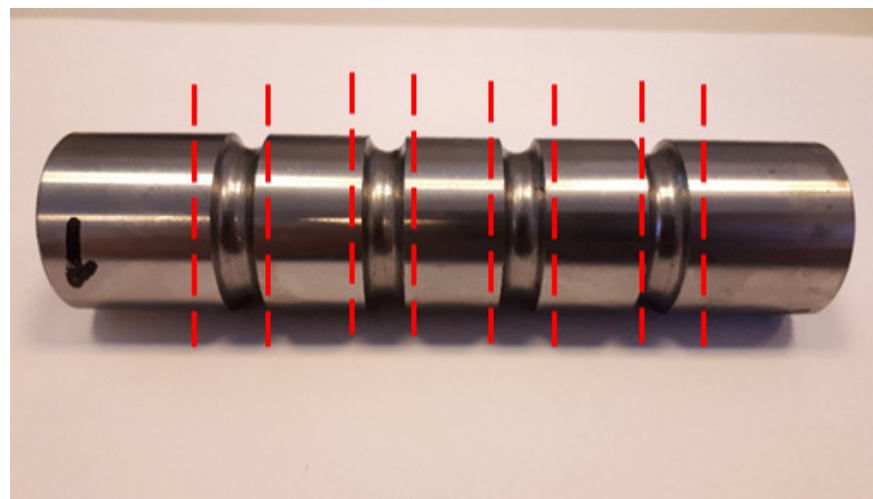

Fig. 8. Hollow shaft with grooves

After hardening, the sections with grooves were cut from the shaft using water jet cutting (Fig. 9). The ring diameter was measured with a micrometer "Limit Micrometer 25-50 mm". Measurements were made 7 times along the circle, minimum and maximum values were excluded and the average value of 5 measurements was calculated. On the next step, rings were transversely dissected on one side (Fig. 3) and the diameter was re-measured perpendicularly to the cut 3 times, the average value of three measurements was calculated. To calculate the ring diameter change after dissection, the 
obtained diameter was subtracted from the initial diameter. The results of the diameter change are shown in the green row of Table 1.

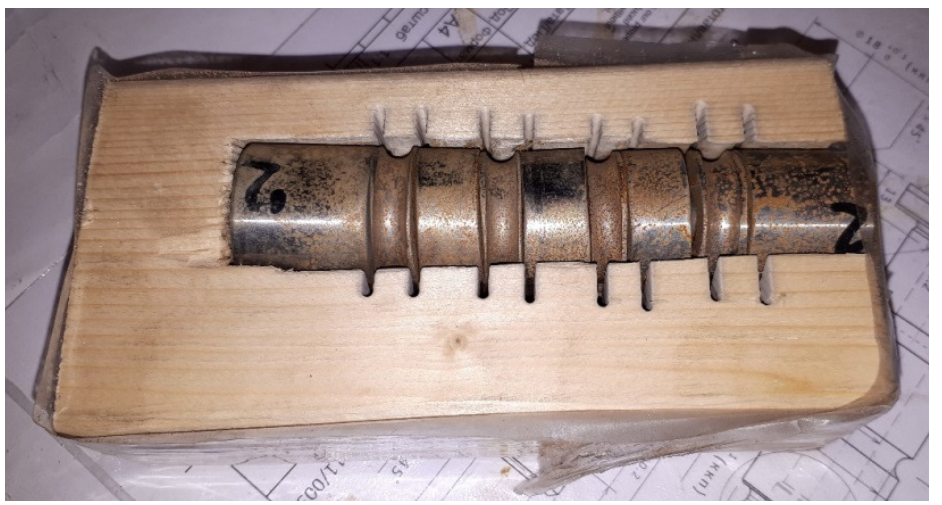

Fig. 9. Transverse shaft cutting into rings

\section{Results and discussion}

FE simulation was verified by series of experiments. The comparison of the results is shown in Table 1. All dimensions in the table are given in millimeters.

Table 1

Experiment results

\begin{tabular}{|c|c|c|c|c|c|c|c|c|c|}
\hline Sample & $\mathbf{1}$ & $\mathbf{2}$ & $\mathbf{3}$ & $\mathbf{4}$ & $\mathbf{5}$ & $\mathbf{6}$ & $\mathbf{7}$ & $\mathbf{8}$ & AVG \\
\hline$\Delta \mathbf{D}$ & 0.033 & 0.013 & 0.017 & 0.035 & 0.034 & 0.036 & 0.036 & 0.032 & 0.030 \\
\hline$\Delta \mathbf{D}($ FEM) & \multicolumn{8}{|c|}{0.038} \\
\hline
\end{tabular}

where AVG - average value of 5 measurements (without maximal and minimal measurements); $\Delta \mathrm{D}$ - decrease in the ring diameter after cutting (experimental);

$\Delta \mathrm{D}(\mathrm{FEM})$ - decrease in the ring diameter after cutting (numerical, FEM results).

Diameter of all rings decreased after dissection. At the same time, the experiment was simulated using the numerical (FE) method, and the numerical diameter change after the ring's dissection is $0.038 \mathrm{~mm}$. The results of 6 samples correlate well with results obtained using FE method, with deviation less than $14 \%$, which confirms legitimacy of this method. Experimental results of samples (No. 2 and No. 3) do not match the numerical simulation with enough accuracy with average deviation of $61 \%$. Possible discrepancy reasons:

- inaccuracy in the ring cutting technology by water jet cutting;

- instability of the rolling technology;

- statistical dispersion;

- correction factor necessity in the numerical analysis (FEM).

\section{Conclusions}

1. After 8 experiments, average deviation of diameter decrease in the experiment and simulation is $21 \%$. In general, the results above show very good potential of this method of FE simulation.

2. After series of calibration experiments, the ring-cutting method could be used as an effective and cheap method for hardening quality control during the manufacturing process.

\section{Acknowledgement}

The research leading to these results has been supported by the European Regional Development Fund project "Development of Competence Centre of Mechanical Engineering", contract No.1.2.1.1/16/A/003 signed between Competence Centre of Mechanical Engineering and Central Finance and Contracting Agency, Research No. 1.12. "Fatigue life improvement of high-loaded parts such as shaft by surface hardening with rolling". 


\section{References}

[1] Juijermi P., Altenberger I. Fatigue performance enhancement of steels using mechanical surface treatments, J. Metals, Mater. Minerals. 17 (1), 2007, pp. 59-65.

[2] Nalla R.K., Altenberger I., Noster U., Liu G.Y., Scholter B., Ritchie R.O. On the influence of mechanical surface treatments -deep rolling and laser shock peeningon the fatigue behavior of Ti6Al-4V at ambient and elevated temperatures, 2003.

[3] Manufacturer manual. Поверхностное Упрочнение Стальных Деталей Обкатыванием и Алмазным Выглаживанием (Surface hardening of steel parts by rolling and diamond smoothing), 2004, pp. 10-11. (In Russian)

[4] Cheng W., Finnie I. Elements of Measurement Using the Slitting Method. Springer, 2007, 10 p.

[5] Hassani-Gangaraj S.M., Carboni M., Guagliano M. Finite element approach towards an advanced understanding of deep rolling induced residual stresses and an application to railway axes, Mater. Des. 83, 2015, pp. 689-703.

[6] Kloos K.H., Fuchsbauer B., Adelmann J. Fatigue properties of specimens similar to components deep rolled under optimized conditions, Internat. J. Fatigue 9, 1987, pp. 35-42.

[7] Altenberger I. Deep rolling - the past, the present and the future, In: Proceedings of 9th international conference on shot peening, 2005, pp. 6-9.

[8] Drozd M.C. Инженерные расчеты упругопластической контактной деформации (Engineering calculations of elastoplastic contact deformation), 1986, pp. 118-119. (In Russian)

[9] Boiko N.I. Ресурсосберегающие Технологии Повышения Качества Поверхностных Слоёв Деталей Машин (Resource-saving technologies for surface layers of machine details quality improving), Moscow, 2006, 70 p. (In Russian)

[10] Birger I.A. Остаточные напряжения (Residual stresses), Moscow, 1963, pp. 106-126. (In Russian) 